FERNANDO LUQUE-

CUESTA

$M A$ CARMEN HIDALGO-

RODRÍGUEZ
Doctorando en Historia y Artes por la Universidad de Granada fernandolc@correo.ugr.es

Profesora Titular del Departamento de Dibujo, Universidad de Granada hidalgor@ugr.es

\title{
Desfragmentación edáfica, social y cerámica. Proyecto artístico centrado en el diseño de platos a partir de restos cerámicos encontrados en el agro de Casabermeja, Antequera y Orce
}




\section{EDAPHIC, SOCIAL AND CERAMIC DEFRAGMENTATION. ARTISTIC PROJECT FOCUSED ON THE DESIGN OF PLATES BASED ON THE CERAMIC REMAINS FOUND IN THE CASABERMEJA, ANTEQUERA AND ORCE FARMLAND}

\section{ABSTRACT}

The main objective of this study is the creation of an artistic ceramic project that reflects the current situation of the rural world as a consequence of industrial agriculture. Current agricultural and livestock production systems have negative environmental consequences, such as erosion and pollution, and cultural consequences, such as rural exodus or the extinction of indigenous germplasm. Through the study of the rural world in the municipalities of Casabermeja, Antequera and Orce, it has been possible to verify the detriment of these lands and their culture and, at the same time, the remains of ceramic plates found in these lands reflect this reality. The methodology used is theoretical-practical: through scientific references, the destruction of pre-industrial agricultural practices is exposed against industrial agriculture; experimentation with agricultural production techniques, both traditional and modern, show their compatibility; and, finally, artistic research, which recovers ceramic remains from the past to design three plates. The artistic work is proposed as an information and awareness means of a world problem, showing the compatibility between production and biodiversity, Nature as a source of culture, and human society as a dependent part of Nature.

\section{Keywords}

Pottery; art; industrial agriculture; rural exodus; drawing

\section{RESUMEN}

Este estudio tiene como objetivo fundamental la creación de un proyecto artístico de cerámica que refleje la situación actual del mundo rural como consecuencia de la agricultura industrial. Los actuales sistemas de producción agrícola y ganadera tienen consecuencias negativas medioambientales como la erosión y la contaminación, y culturales como el éxodo rural o la extinción de germoplasma autóctono. A través del estudio del mundo rural en los municipios de Casabermeja, Antequera y Orce, se ha podido comprobar el detrimento de estas tierras y su cultura y, al mismo tiempo, en los restos de platos cerámicos hallados en estos terrenos se encuentra el reflejo de esta realidad. La metodología usada es teórico-práctica: mediante referentes científicos se expone la destrucción de las prácticas agropecuarias preindustriales frente a la agricultura industrial; la experimentación con técnicas de producción agrícola, tanto tradicionales como modernas, evidencian su compatibilidad; $y$, finalmente, la investigación artística, que recupera restos cerámicos del pasado para diseñar tres platos. La obra artística se propone como medio divulgativo y de concienciación de un problema mundial, evidenciando la compatibilidad entre producción y biodiversidad, la Naturaleza como fuente de cultura, y la sociedad humana como parte dependiente de la Naturaleza.

\section{Palabras clave}

Cerámica; arte; agricultura industrial; éxodo rural; dibujo 


\section{INTRODUCCIÓN}

Esta investigación forma parte de la tesis doctoral titulada "El arte como herramienta crítica y de reivindicación cultural. Propuestas artísticas frente a la erosión y pérdida de cultura provocadas por la agricultura y ganadería industriales en Casabermeja, Antequera y Orce", que se está llevando a cabo en la Universidad de Granada. En esta tesis se estudian las consecuencias de la agricultura industrial en el mundo rural a partir de estos tres pueblos representativos del agro andaluz, con objeto de hacerlas visibles y concienciar a la sociedad de la necesidad y posibilidad de un cambio en los métodos de actuación. La reivindicación de este cambio se materializa en la creación de diferentes obras artísticas como son una novela gráfica, ilustraciones sobre procesos evolutivos relacionados con la agricultura, dibujos científicos sobre especies en peligro de extinción, y la obra de cerámica que se presenta como resultado de esta aportación. Como parte importante de esta tesis se encuentra el trabajo de campo, que comprende sobre todo una experimentación in situ de los métodos de agricultura tradicional, también combinados con métodos industriales, que permiten conocer de primera mano las ventajas e inconvenientes de los mismos. Durante el desarrollo de esta fase de trabajo más experimental se encontraron restos de platos que dieron origen a la obra que se presenta aquí.

Hoy en día, la realidad rural comprende una lucha entre la agricultura industrial, y la agricultura ecológica y preindustrial. Aunque la agricultura industrial venía desarrollándose desde comienzos del siglo XX, es entre 1940 y 1970 cuando se consolida a través de la llamada Revolución Verde (Martínez-Centeno y Huerta-Sobalvarro, 2018). La Revolución Verde fue la designación dada a la explosión productiva, basada en un gran uso de agroquímicos, maquinaria y variedades intervenidas genéticamente (Ceccon, 2008). En resumen, la industria basada en el petróleo llegó al sistema de producción, declarando la guerra a las prácticas agropecuarias que se venían haciendo desde tiempos inmemoriales.

La contienda entre los sistemas de producción está directamente relacionada con la contaminación, la erosión y la pérdida de biodiversidad a nivel medioambiental. No obstante, y tal y como dice Joan Martínez Alier:

En un conflicto ambiental se ven involucrados valores muy distintos, ecológicos, culturales, de subsistencia de las poblaciones, y también valores económicos. Son valores que se expresan en distintas escalas, no son conmensurables. Como dijo Machado, "Todo necio / confunde valor y precio". (Martínez-Alier, 2005, p. 43)

Así, el conflicto ambiental que supone la agricultura industrial también tiene unas consecuencias culturales como el éxodo rural, la ruina del patrimonio agrario y la extinción de germoplasma autóctono (Acosta-Naranjo, 2008). La cultura ligada a la agricultura antigua se ha perdido tanto en las zonas abandonadas como en las intensificadas a nivel productivo. Una cultura que abarca lo material, como, por ejemplo, las artesanías, las edificaciones o las herramientas; y lo inmaterial, como el conocimiento sobre la tierra, los cultivos y el ganado, y el arte popular ligado directamente a la agricultura y la ganadería (Luque-Cuesta y Hidalgo-Rodríguez, 2020). Cabe destacar la cantidad de oficios y objetos desaparecidos como consecuencia cultural del nuevo sistema de producción, dentro de los cuales destaca la cerámica en este caso, desde su elaboración hasta su uso y destrucción. En 1974, Juan Antonio Hormigón ya advertía del peligro que este arte corría: 
Las formas productivas capitalistas, su noción de rendimiento y valor de la mercancía son incompatibles con la alfarería popular española de forma sustancial. En la mentalidad capitalista, la cerámica de uso es una antigualla medieval. [...] El pronóstico, hoy por hoy, es muy grave: nuestra cerámica popular agoniza. (Hormigón, 1974, p. 36)

Tras casi cincuenta años, las palabras que Juan Antonio Hormigón se han tornado proféticas: apenas quedan alfareros hoy día en España, y menos en Andalucía. La cerámica de uso, paradójicamente rota en su uso, nunca se reemplazó tras la implantación del sistema de producción industrial. De esta manera, la destrucción de esta cerámica supone un punto de inflexión como simbología de los oficios perdidos y la creación de la obra artística que se propone. A partir de los fragmentos encontrados -como resultado de la vajilla rota accidentalmente por los campesinos que comían en el campo- se comparan los sistemas de producción industriales y antiguos, así como las sociedades que los llevan a cabo.

En este artículo, por tanto, se expone el desarrollo creativo de esta obra cerámica, que representa la historia más reciente del mundo rural. Historia que permanece en la memoria colectiva de los protagonistas y que merece ser visibilizada como contrapunto al lamentable estado actual del medio ambiente.

En consecuencia, la hipótesis sobre la que se construye este estudio se centra en que la cerámica rota hallada en el campo de Casabermeja, Antequera y Orce, puede convertirse en reflejo del detrimento de la relación entre la Sociedad y la Naturaleza en los pueblos. El objetivo fundamental para llevar a cabo esta investigación se enfoca en el diseño de tres platos que, no solo serán representativos de los cambios en el sistema de producción, sino también de las consecuencias medioambientales y culturales más inmediatas. Además, estos platos serán el inicio de una colección mayor que dará lugar a un proyecto expositivo.

\section{METOdología}

El desarrollo de la creación artística ha sido posible gracias al recorrido por tres fases de trabajo fundamentales. En primer lugar, el trabajo de campo, que se basa sobre todo en actividades de naturaleza preindustrial, realizadas en Casabermeja, Antequera y Orce. Estas actividades forman parte de la tesis mencionada anteriormente y consisten en tareas agropecuarias preindustriales como el arado animal, el cuidado de cultivos antiguos o el pastoreo extensivo, con objeto de comparar el impacto ambiental respecto a la producción industrial. El acercamiento al modo de vida preindustrial también lo hizo a los restos que el mismo dejó en el campo: los fragmentos cerámicos. Su hallazgo, si bien fue casual en un primer momento, se convirtió pronto en el resultado de una búsqueda documentada, donde ha sido de vital importancia la visita del patrimonio arquitectónico rural en base a la información dada por los lugareños. Dado que el factor humano ha sido de vital importancia y la recopilación de datos se ha basado especialmente en testimonios de la gente del campo, la metodología de este proyecto es de corte cualitativa.

En segundo lugar, se ha realizado un estudio bibliográfico para comprender la plenitud de las obras; es importante explicar la historia de la cerámica y el barro, estrechamente ligada a las sociedades y culturas agrícolas, y siendo su origen (paleolítico o neolítico) objeto de confrontación en la comunidad arqueológica (Jordan y Zvelbil, 2009). No se hace un análisis histórico exhaustivo de la historia de la cerámica, sino una reflexión filosófico-histórica, donde se asocia la cerámica a la agricultura preindustrial para, finalmente, elaborar un mensaje complejo 
que se divulgará a través de las obras artísticas propuestas. Los valores y la simbología atribuidos a la cerámica por culturas precedentes enriquecen los fragmentos cerámicos encontrados y la nueva obra.

En paralelo, se ha estudiado el arte cerámico popular a partir de los restos cerámicos encontrados y, mediante hipótesis visuales, se han hallado las soluciones ornamentales más utilizadas por los antiguos ceramistas. Los platos cerámicos que fueron encontrados completos sirven como guía para la reconstrucción visual y tridimensional de los mismos (en cuanto a forma y tamaño), teniendo en cuenta el grosor de los fragmentos.

En último lugar, destaca el diseño de nuevos platos con ilustraciones simbólicas y narrativas inspiradas en los restos encontrados, desarrollando una investigación basada en las artes, concretamente en la práctica artística, donde el proceso y la experimentación cobran la misma importancia que el resultado final. La práctica artística se aborda desde el concepto de la $a / r /$ tografía, una forma de indagación que forma parte de la PBR [practice-based research], que incluye prácticas de los artistas, los educadores y los investigadores (Irwin, 2013, p. 107). El proceso de diseño parte de una simbología atribuida a la cerámica rota encontrada, así como de una lectura artística. La resignificación de estos objetos anecdóticos, como son los fragmentos cerámicos, permite hablar de mensajes complejos como la degradación de la cultura rural y la pérdida de biodiversidad.

Estas tres fases de trabajo dan lugar a la estructuración del artículo en los siguientes capítulos: el marco teórico, que recoge el campo de actuación de la investigación y su justificación, una reflexión sobre el origen y evolución de la cerámica de uso, y la resignificación que se hace sobre los restos encontrados que servirán como punto de partida a la creación artística; la creación artística, que abarca lo encontrado en el trabajo de campo, su análisis y el desarrollo del diseño de los platos; $y$, finalmente, las conclusiones y referencias bibliográficas.

\section{MARCO TEÓRICO Y CONCEPTUAL}

Los pueblos que forman el Triángulo CAO (iniciales de los pueblos Casabermeja, Antequera y Orce), al igual que la mayoría que se originaron tras la Revolución Agrícola, tenían un modo de vida basado en la continua interacción con el medio natural en el que se asentaban, ya fuese mediante la caza y recolección (economía paleolítica) o mediante la agricultura y la ganadería. El estilo de vida fue muy parecido durante aproximadamente 10.000 años, donde la energía que alimentaba a la población provenía exclusivamente del trabajo de campesinos y animales. Con la Revolución Industrial, la energía mecánica comienza a trasladarse paulatinamente al campo, potenciando la producción y transformando la pirámide social (Chaves, 2004). No obstante, la industrialización del campo andaluz sería una de las más tardías en Occidente, debido, en gran parte, al latifundismo (González de Molina, 2014) y la orografía del terreno (Molina-González et al, 2000). Las zonas poco accidentadas (vegas de Antequera y Orce, y campiña de Casabermeja) se industrializarían antes por la posibilidad de mecanizar la producción, del mismo modo que fueron repartidas entre los latifundistas también en un momento anterior. Por otro lado, las zonas accidentadas (Sierras de Antequera y Orce, y montes de Casabermeja) no se podían mecanizar, por lo que se dividían en pequeñas propiedades donde finalmente se abandonaría la producción. 
La presencia de campesinado en Andalucía hasta hace relativamente poco, junto al abandono de las tierras no mecanizables, son los principales motivos por los que se pueden encontrar fragmentos cerámicos en el agro andaluz, teniendo los más recientes alrededor de cincuenta o sesenta años de edad. Los fragmentos cerámicos constituyen las palabras de un mensaje, aquél que nos habla de una realidad, donde la mayor parte de la población andaluza vivía en el campo. Nacían en los pueblos, trabajaban las tierras de las que comían y donde comían, y morían en los pueblos. La mayor cantidad de fragmentos cerámicos han sido hallados en tierras de labor accidentadas no mecanizadas (en el caso de Casabermeja), o abandonadas (en los casos de Antequera y Orce), de ahí su importancia como huella y testigo del modo de vida preindustrial. Los fragmentos cerámicos permiten unir Casabermeja, Antequera y Orce de forma material, al mismo tiempo que vinculan la tierra al impacto de la agricultura industrial. Las iniciales CAO representan la realidad actual de la sociedad campesina andaluza.

La forma circular del plato potencia la unión simbólica de los municipios del Triángulo CAO, y su superficie será la base para representar una realidad social en el campo andaluz del pasado más reciente. El atractivo de estas sociedades reside en su impacto en el medio natural; pese a que hubiese una mayoritaria población rural, el impacto ambiental era mucho menos agresivo que el de hoy día, momento en que apenas vive gente en el campo. A través de conversaciones y entrevistas con personas no relacionadas entre sí, se ha constatado la enorme presencia de personas, fauna y flora en el campo, algo que es contrario a la creencia extendida por la mayor parte de la población "concienciada" (grupos ecologistas en especial).

La Figura de Homo sapiens dentro de la naturaleza se ha demonizado, extendiéndose la creencia de que, inevitablemente, nuestra presencia en la naturaleza es fatal para el resto de formas de vida. Pese a que a lo largo de la historia hemos mostrado ser fatales para otras formas de vida, siempre fue de forma directa, a través de la caza (especialmente en la sociedad paleolítica). El problema es que se ha relacionado directamente estas extinciones prehistóricas con las que ocasiona el sistema de producción de hoy día, como si de una evolución de la extinción se tratase. Homo sapiens es responsable de la nueva gran extinción, el Antropoceno, que supondrá una pérdida de entre el $20 \%$ y el $50 \%$ de las especies (Manrique, 2015). No obstante, la forma en que se extingue ha cambiado radicalmente: antaño fue con la caza de subsistencia, ahora, con la agricultura y ganadería (ocupación de tierras, manejo intensivo y contaminación del terreno). A medio camino, entre economía paleolítica y economía industrial, y junto a los avances tecnológicos, se encuentra la solución para explotar la naturaleza de forma sostenible.

Los testimonios dejados por quienes utilizaban cerámica, los que comían en el campo, dicen que se puede vivir en armonía con otras formas de vida, en base a lo que ellos vivieron. Así pues, el origen de esta demonización humana en la Naturaleza reside en la agricultura industrial, de gran impacto ecológico, ya que es a partir de su consolidación (como parte de la sociedad industrial) cuando la extinción se ha incrementado y acelerado (Ceballos et al, 2015). La relevancia de esta afirmación reside en su potencial futuro: si la sociedad cree que se puede tener un impacto positivo en la Naturaleza con la producción de alimentos, habrá más posibilidades de desarrollar sistemas de producción sostenibles y con impacto positivo. Como ejemplo ilustrativo, en la Figura $1 \mathrm{~A}$ se muestra uno de los muchos nidos encontrados en almendrales experimentales, y difícilmente visibles en un almendral industrial. El trabajo de Geoff Lawton, en Jordania, muestra cómo producir con impacto positivo en el medio (Figura 1B), pues ha creado desde 2008 un vergel productivo en el desierto. 


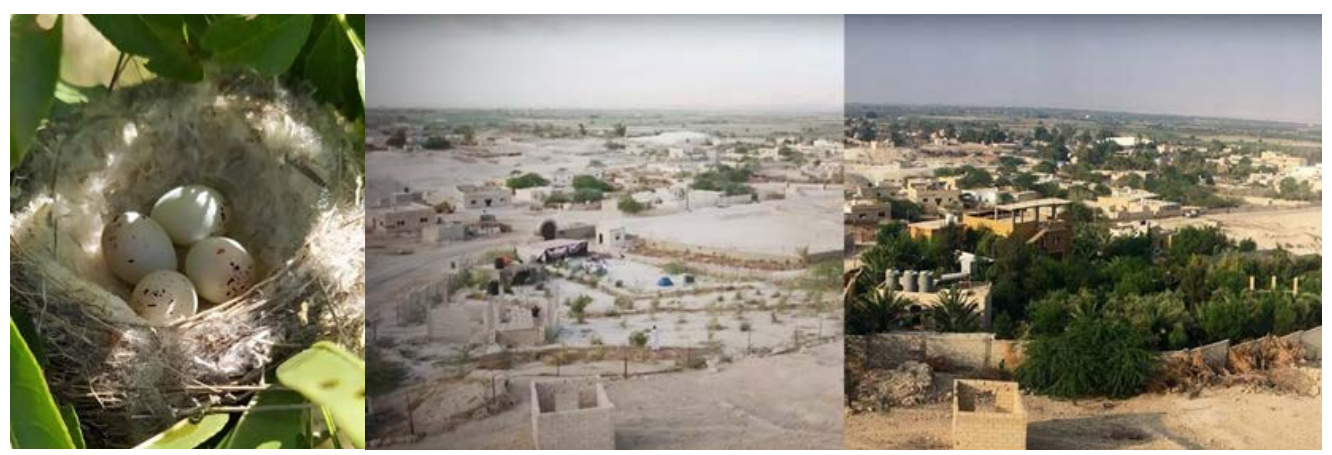

Figura 1. Figura 1A. Nido de jilgueros en un almendral manejado de forma experimental en Casabermeja en 2019. Fuente: fotografía del autor. Figura 1B. Comparativa del proyecto “Greening Desert Jordan”, entre 2008 y 2018 , de Geoff Lawton. Fuente: Discover Permaculture with Geoff Lawton. Recuperado de: https://i.ytimg.com/vi/W69kRsC_ $\mathrm{CgQ/maxresdefault.jpg}$

Aunque cada pueblo tenía sus talleres cerámicos para construcción de tejas, elaboración de vasijas, cántaras y platos, los motivos y formas eran muy parecidos. Se han hallado tres tipos de platos en el triángulo $\mathrm{CAO}$, cuyos pueblos compartían el duro modo de vida preindustrial: los platos con esmaltes marrones y decorados lineales en blanco o amarillo; los platos con esmalte blanco y decoración plana en azul; y los platos completamente verdes. Podría decirse que el plato es el modo de vida, y los fragmentos los pueblos que lo llevaban a cabo.

\subsection{Del dios alfarero a la cerámica de uso}

Antes de cocerse, la cerámica es arcilla modelada seca y antes aún es barro amorfo: tierra y agua que se mezclan hasta obtener una masa moldeable. Al cocerse forman la terracota, literalmente tierra cocida, teniendo en cuenta las raíces latinas de las que procede el término, terra y coctus. La terracota fue el primer material manufacturado por el hombre, y de ahí que la mayor parte de las culturas tengan leyendas que asocian el barro a la formación humana, normalmente por parte de algún dios.

Fueron muchos los dioses creadores alfareros, de diversas culturas, que protagonizaron el acto de creación de la Humanidad. Según el poema babilónico Enûma Elish (Anónimo, 1989), el dios Enki creó al hombre con el barro resultante de mezclar la sangre del demonio Kingu y la tierra (VI:30); en la mitología Sumeria y según cuenta el Poema de Gilgamesh I:2 (Anónimo, 2003), la diosa Aruru modeló la arcilla para crear al héroe Enkidu; en el Antiguo Egipto, el dios Khnum era quien modelaba a los humanos, hasta que cansado puso un fragmento de su torno en cada mujer para relegar en ellas su tarea (Thode \& López, 1999); Prometeo y Atenea modelan el primer hombre en la mitología griega (Ovidio, trad. 2003). A nuestros días ha llegado ese Dios alfarero por parte de las religiones abrahámicas y los textos del Antiguo Testamento, concretamente en el Génesis (2:7), donde se escribe que Dios cogió la tierra y formó al hombre. 


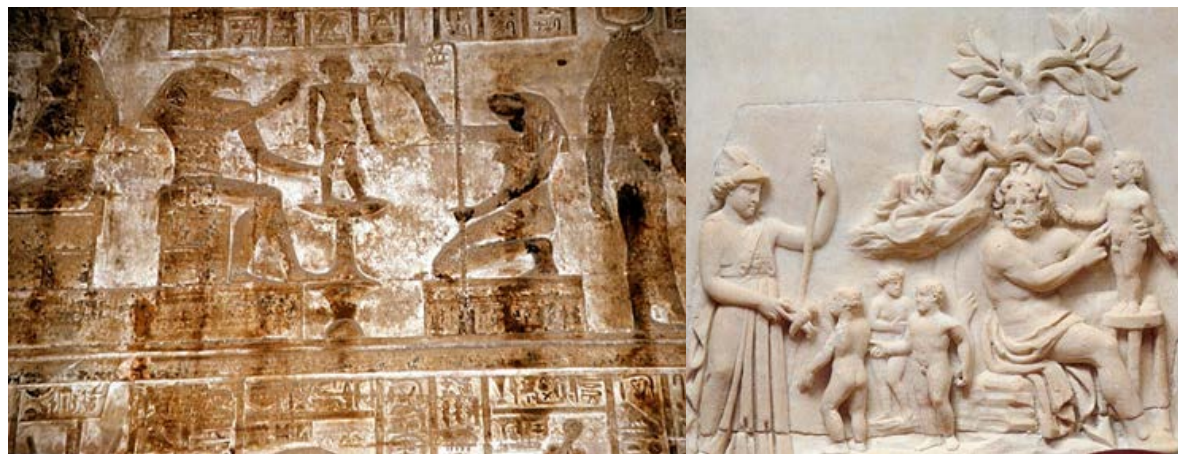

Figura 2. Mitos de la creación de la Humanidad. De izquierda a derecha: Figura 2A. Egipto. Fuente: Roland Unger, 2000. Recuperado de: https://es.wikipedia.org/wiki/Archivo:DendaraMamisiKhnum-10. jpg. Figura 2B. Grecia. Fuente: Anónimo. Recuperado de: http://www.uco.es/ ca1lamag/Galerias/ Prometeomodelando.jpg

El origen cerámico es una de esas cuestiones que activa la imaginación. Quizás, un grupo de Homo habilis hiciese una hoguera en la orilla de un río, en un pequeño hoyo para que el viento no avivase el fuego. A la mañana siguiente, oculta bajo las cenizas, habría una terracota primitiva, que pasaría desapercibida para el grupo. No sólo para los habilis, sino para los sapiens, cuyos restos más antiguos datan de hace 315.000 años (Hublin et al, 2017), pero de los que la terracota más antigua data de hace tan solo 20.000 años (Wu et al, 2012). Esto probablemente se deba al asentamiento de los humanos en zonas ricas en fibras vegetales, que les permitían elaborar recipientes de almacenaje. Diferentes autores como Bender (1978) y Testart (1988) ven en el hecho de almacenar una de las causas de la Revolución Neolítica, siendo éste el origen de la propiedad privada y la riqueza material, capitalista. Así, los grupos nómadas sapiens no necesitarían grandes recipientes en los que almacenar, diferentes a los sapiens semisedentarios, que desarrollaron la industria cerámica.

En cualquier caso, la elaboración de la cerámica parte de una distinción y separación de los elementos: la tierra se moja con agua para moldearla; el aire la seca; y el fuego, finalmente, forma el primer material manufacturado. No hay otro orden posible para realizar cerámica. En la elaboración de platos cerámicos se encuentra una conexión con las sociedades más primitivas -de las que somos herederos- mediante los cuatro elementos de la Naturaleza, que marcaron a su vez el desarrollo de multitud de mitologías. Del mismo modo, este material primigenio está estrechamente vinculado a la cocina, no solo por contener alimento, sino por la necesidad de una receta, de ingredientes y una elaboración. Si damos por válida la hipótesis del antropólogo y primatólogo Richard Wrangham (2009), que dice que fue la cocina con fuego aquel fenómeno que transformó nuestro cuerpo (reducción de tripas y arco bucal, mayor asimilación de nutrientes, crecimiento cerebral y más tiempo para pensar), se podría decir que el barro debía ser el material manufacturado primigenio por derecho propio, tratándose de "tierra cocinada". El gran desarrollo cerámico a partir de las sociedades neolíticas (si bien pudiera haber existido cerámica paleolítica) lo vincula directamente a la agricultura.

Todos los pueblos y culturas, desde el Neolítico, han dejado arte cerámico en el que reflejaban la imaginación colectiva, las formas de vida y de ver el mundo que tenían, a través de distintos estilos. Las cerámicas y sus ornamentaciones son distinguibles entre las culturas, aunque guarden parecidos entre ellas (colores, esquematizaciones, composición). Una porcelana 
china de la Dinastía Ming es no solo fácilmente diferenciable de una cerámica nazarí del Reino de Granada, sino también de otras dinastías chinas como la Tang. No obstante, la cerámica evolucionó en forma, ornamentación y uso, igual que hicieran las culturas que las crearon, y en consecuencia los estilos tienen un nacimiento, una evolución y una muerte, como las culturas de las que forman parte.

Esta gran riqueza artística se debe a que la cerámica no deja de ser un formato que, además de poderse modelar en todo tipo de formas, ofrece total libertad creativa a la hora de ser adornada. No obstante, los artesanos y artistas se acogían al estilo de su pueblo y su arte, a diferencia de los artistas contemporáneos, que utilizan el formato como un lienzo.

\subsection{Lectura artística y simbología atribuida a la cerámica encontrada}

Se ha escrito mucho sobre las distintas técnicas de la cerámica, como hicieran Mattison (2003) al hablar de las herramientas y técnicas básicas para esta disciplina, y Reijnders (2005), quien además animaba a la experimentación cerámica como parte del éxito alfarero. La adaptación artesanal a las nuevas facilidades tecnológicas viene de la mano de Mella Márquez (2011) que, además de analizar los avances técnicos, propone la innovación empresarial en zonas de tradición cerámica con el fin de que la actividad perviva. Pese a la gran bibliografía escrita, la mayoría coinciden en que para cocer el barro la pieza no debe ser demasiado gruesa, hallándose el grosor ideal entre el medio centímetro y los dos centímetros. En caso de ser una cerámica de bulto redondo, el grosor se controla con el ahuecado antes de que la pieza se seque, aportando así estructura interna, y además este grosor debe ser regular en toda la pieza. En el caso de los platos y vasijas habrá que controlar el grosor de los mismos durante el modelado, para que no exploten ni se resquebrajen en el secado y en el horneado.

En platos y vasijas puede verse una semejanza con el edafón, que posibilita los ciclos vitales en la tierra, además de darnos alimento. La palabra "edafón" la crea Raoul Heinrich Francé (1913), quien la define como el conjunto de organismos que habitan en el suelo. Los platos y vasijas pueden ser una representación de este edafón al ser el soporte sobre el que literalmente colocamos la comida, ya sea para conservarla (orzas llenas de manteca o tinajas de vino) o para consumirla (platos de mesa o fuentes). Al igual que los platos, el edafón ha desaparecido de los campos de cultivos debido al uso excesivo de productos químicos y al continuo laboreo mecánico.

Una vez que está el plato en la mesa, o en el suelo (en caso de comer en el campo), entre la terracota y los alimentos se encuentra la decoración, que puede ser incisiva (estampación de texturas, dibujo con punzones...) o superficial, a través de pintura con esmaltes y engobes. La decoración de vasijas y platos no hace sino potenciar esta simbología y correlación edáfica. ¿Qué se solía representar en los platos? Animales y plantas, los macro organismos que viven sobre el edafón, a los que deben su vida y de los que forman parte, especialmente al morir. El esmalte apenas suele tener un milímetro de grosor que, en comparación con la terracota, puede suponer menos de una décima parte del total del volumen cerámico. La decoración pintada es una metáfora perfecta que representa la fragilidad de las criaturas terrestres, dependientes del edafón sobre el que viven e igualmente vulnerables.

A través de los platos no solo se habla del suelo como continente (en cuanto que están hechos de suelo cercano a donde son hallados), sino como contenido (en ellos se come lo que el suelo 
produce, sobre el suelo que lo produce). Mediante el plato se puede hablar de Homo sapiens como parte de la Naturaleza, además de la belleza de los ciclos naturales: nacimiento y vida, crecimiento y desarrollo, y muerte e integración en el suelo. Esta filosofía queda asociada directamente al material, el barro; un material inorgánico que sirve para hablar de unos ciclos orgánicos, de seres vivos. La forma circular de los platos refuerza esta simbología cíclica y simbiótica perfecta.

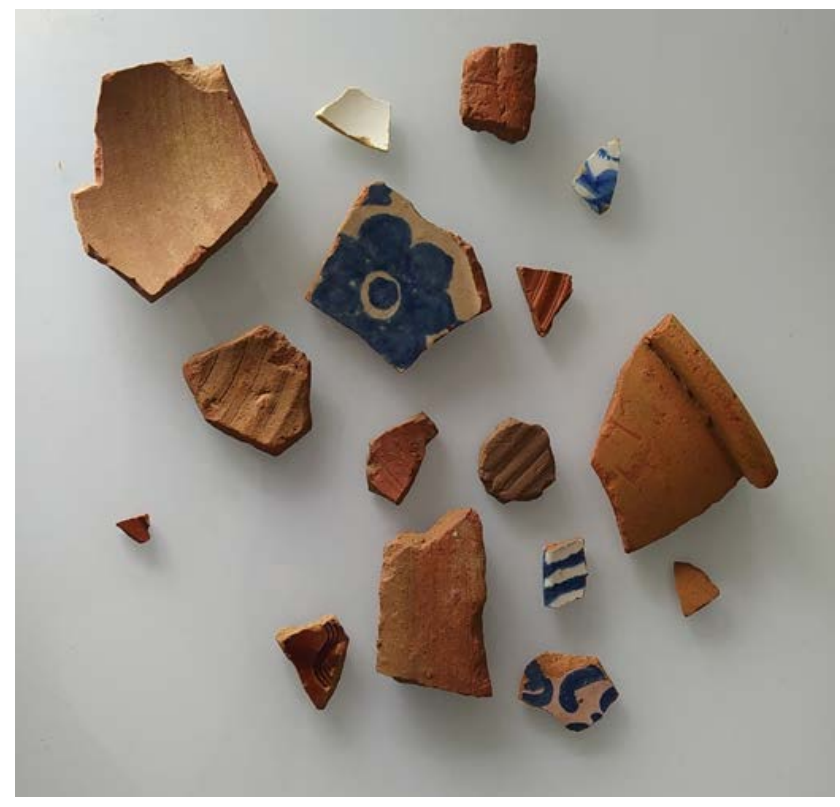

Figura 3. Fragmentos de platos hallados en Casabermeja en 2019 y 2020. Fuente: fotografía del autor.

Los fragmentos de platos encontrados (Figura 3), que simbolizan los pueblos, también encierran un destino romántico que potencia la dualidad de vida y muerte, y que se ve acentuado si nos centramos en las palabras de Orton, Vince y Tyers (1997): "Hablar de la alta visibilidad de la cerámica nos lleva al punto donde suelen iniciarse las discusiones en torno al valor arqueológico de la cerámica: su ubicuidad y aparente indestructibilidad" (p. 47). La confrontación en el ámbito científico no solo potencia este romanticismo, sino que hace obligatorio el estudio de la ornamentación y manufacturación cerámicas para datar los restos hallados. Los platos se rompían en el campo mientras se usaban para el motivo por el que se fabricaban: comiendo. A su vez, comer es lo que mantiene la vida. Incluso en "la muerte del plato", cuando se hacía añicos, éste se integraba en el suelo, ofreciendo refugio a multitud de edafofauna. La arcilla es muy porosa, llegándose a utilizar bolas de arcilla cocida en jardinería y agricultura ecológica por los beneficios que tiene (airear el suelo, mejorar el intercambio entre agua y aire, y albergar microbiota).

Los restos de platos representan esa sociedad unida a la Naturaleza, así como una huella humana asimilable por el medio ambiente (Figura 4), muy diferente a los platos de plástico y otros deshechos inorgánicos que se pueden encontrar contaminando cualquier campo en la 
actualidad. Así mismo, permite una reflexión filosófica que naturaliza y asimila la dicotomía entre vida y muerte.

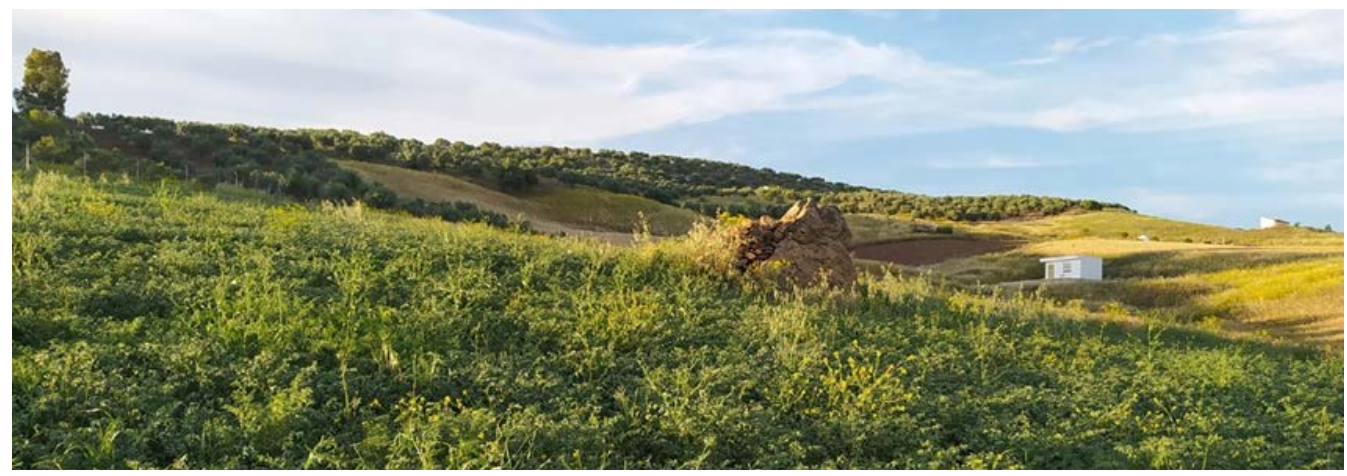

Figura 4. Garbanzal manejado de forma preindustrial en 2019, donde se hallaron restos cerámicos. Pese a ser un terreno agrícola productivo, presenta gran biodiversidad y poco riesgo de erosión. Fuente: fotografía del autor.

En este aspecto, los fragmentos cerámicos perdidos en el suelo agrícola pueden representar un fiel retrato de nuestra sociedad. Una sociedad de origen rural, hoy día completamente desconectada entre sí, donde los individuos priman sobre el conjunto. Una sociedad cuyos hábitos de consumo y producción ha roto la estructura del suelo, el mismo suelo donde antaño se rompieron los platos.

\section{CREACIÓN DE LA OBRA ARTÍSTICA}

Conceptualmente, se encuentra una similitud entre el origen de la obra presentada y el proceso seguido por algunos artistas que rescatan objetos desechados o encontrados casualmente para generar su obra artística. Cada vez son más los artistas que trabajan para concienciar a la población sobre la necesidad de cuidar el medioambiente, y prueba de ello es la asociación Arte y Concienciación Social, que pretende ayudar a visibilizar el trabajo de este tipo de artistas.

Dentro de los artistas que trabajan la concienciación ecológica, se encuentra un parecido estético con la artista Mandy Barker, que fotografía restos de plásticos hallados en el interior de animales. Los fragmentos de plástico son colocados sobre un fondo negro para potenciar la ilusión de fragmentación e integración inorgánica en la Naturaleza (Figura 5). La basura hallada también puede componer obras figurativas a través del collage, como las realizadas por Vik Muniz en 2008 con restos hallados en vertederos. De este modo, algunos artistas se valen del reciclaje y la concienciación para reivindicar el material de desecho y su potencial para generar arte, convirtiendo el proceso artístico en un arte en sí mismo por su valor investigativo. Siguiendo a Irwin (2013) y su concepto de a/r/tografía, la misma "es una indagación de vida, un encuentro personal llevado a cabo mediante comprensiones y experiencias artísticas y textuales, así como por representaciones artísticas y textuales" (p. 108). 


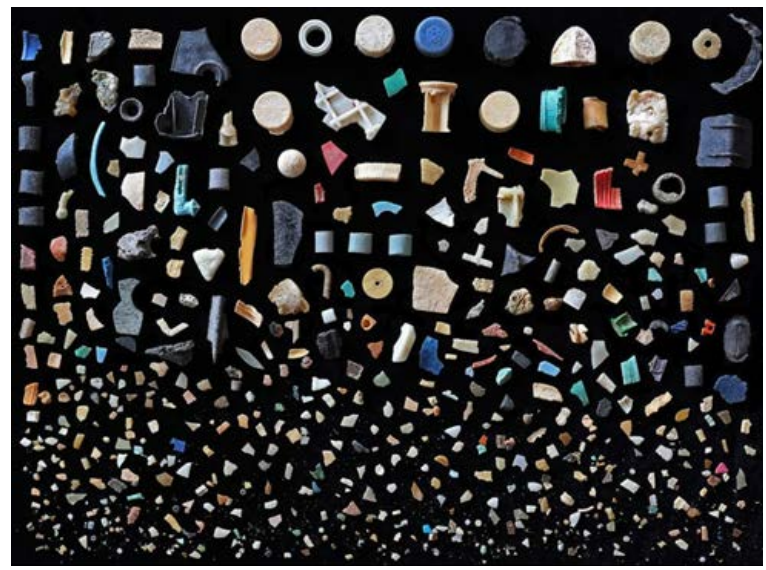

Figura 5. Mandy Barker, 276 Inside - Out, 2015. Fotografía de 276 plásticos hallados en el estómago de un polluelo de albatros de 90 días. Fuente: https://www.mandy-barker.com/commissions

En el caso que se propone, la cerámica se convierte en un soporte con mayor relevancia que pudiera tener un papel, siendo un lienzo en blanco con gran carga simbólica sobre el que dibujar. El acercamiento a esta disciplina, curiosamente, no se hace desde su creación, sino desde su destrucción.

El primer fragmento cerámico fue encontrado en diciembre de 2019 , en la primera salida de campo con un ganadero extensivo: un trozo de un plato donde se ve una flor de siete puntas en azul (Figura 6). El fragmento, grande, se encontraba sobre la hierba verde, aún corta por la falta de lluvia. Orientado al sur reflejaba la luz del sol, que llamó la atención al bajar por una pendiente. El ganadero al que se acompañaba, apodado Colmena, explicó rápidamente la naturaleza del objeto:

\footnotetext{
¿Tú sabes eso de que es, Fernandillo? De que antiguamente la gente comía en el campo, y lo mismo se te rompía un plato que un botijo. Anda que no se rompían botijos en el campo. Así que ese trozo de plato puede llevar muchísimos años por aquí rociado. (Tengo un conflicto interior y no sé si llevármelo o dejarlo. Me lo llevo.) A ti te pasa como a mí, que veo una herradura en el campo y me la llevo, sin tener bestia niná. (Transcripción de la conversación mantenida con Colmena, 2019)
}

Tras ese fragmento vinieron muchos otros. Cientos de fragmentos cerámicos, de los que no se había sido consciente antes, comenzaban a aparecer en zonas transitadas alguna vez. Pese a no haber una motivación definida, los fragmentos se recogieron.

La cerámica no sólo se encontró en mitad del campo, sino alrededor de los edificios agrarios, hallados en ruinas en su mayoría. Cortijos, caseríos, casas cueva, molinos o lagares, son solo algunas de las construcciones agrarias a merced de los elementos en los que se pueden hallar testimonios materiales de la sociedad campesina andaluza, en este caso cerámicas rotas. En ocasiones presentaban mucha resistencia; el suelo, algunas veces endurecido y abandonado, los tenía perfectamente incrustados (Figura 7). Trozos esmaltados o sin esmaltar, fina o bruscamente decorados, grandes o pequeños se comenzaron a amontonar en el estudio, donde se separaban según su lugar de procedencia. Había comenzado, de este modo y de forma azarosa y natural, el proceso artístico, de forma inconsciente. 


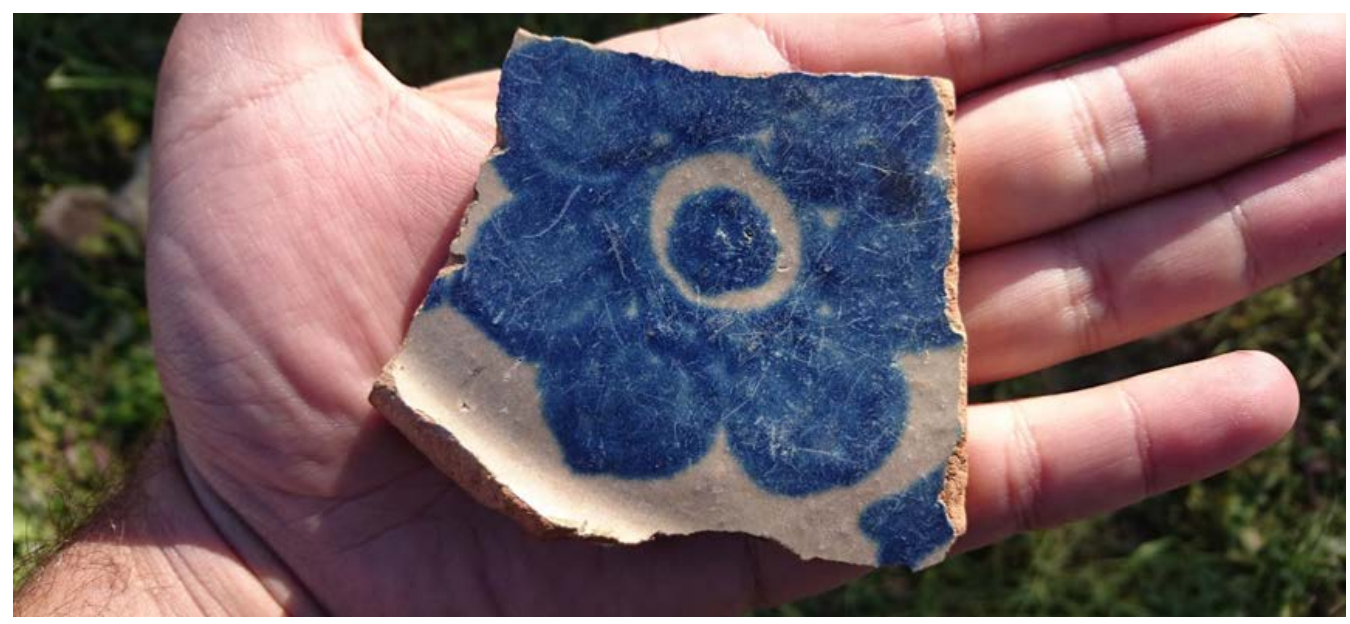

Figura 6. Primer fragmento encontrado, diciembre de 2019. Fuente: fotografía del autor.

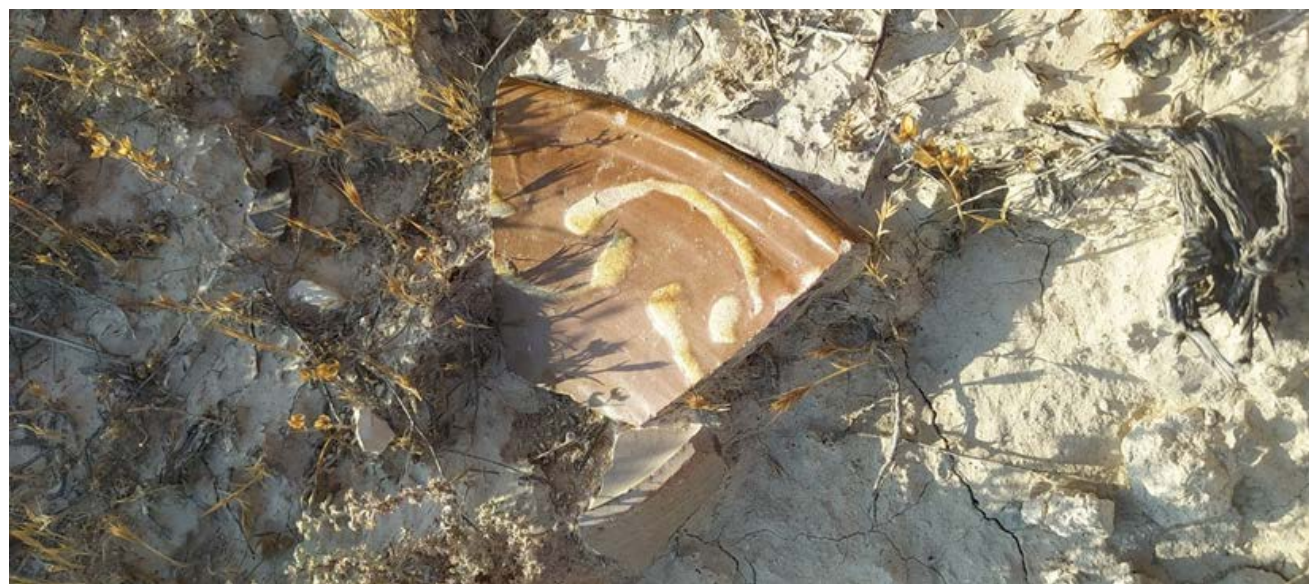

Figura 7. Fragmento incrustado en el suelo en 2020, en una casa cueva abandonada en los alrededores de Orce. Fuente: fotografía del autor.

De por sí, el paisaje donde se encontraban los fragmentos le daban a los mismos un valor emocional. Algunos se encontraban arando con mulos, otros cogiendo almendras, muchos paseando en zonas de cultivo abandonadas o ruinas de casas y cortijos. Aunque no se conoce el lugar preciso al que pertenece cada una de las piezas (alrededor de trescientas), algunas de ellas, como la primera, transportan a su lugar de origen y a las personas que han ayudado a recogerlas, gente que gusta de andar por el campo. 


\subsection{Proceso Creativo}

El proyecto artístico, iniciado en diciembre de 2019 , ha sido largo, dando origen a multitud de bocetos e ideas (Figura 8) que han surgido alrededor de estos fragmentos cerámicos, así como una serie de obras artísticas finales, cargadas de simbología y mensajes.

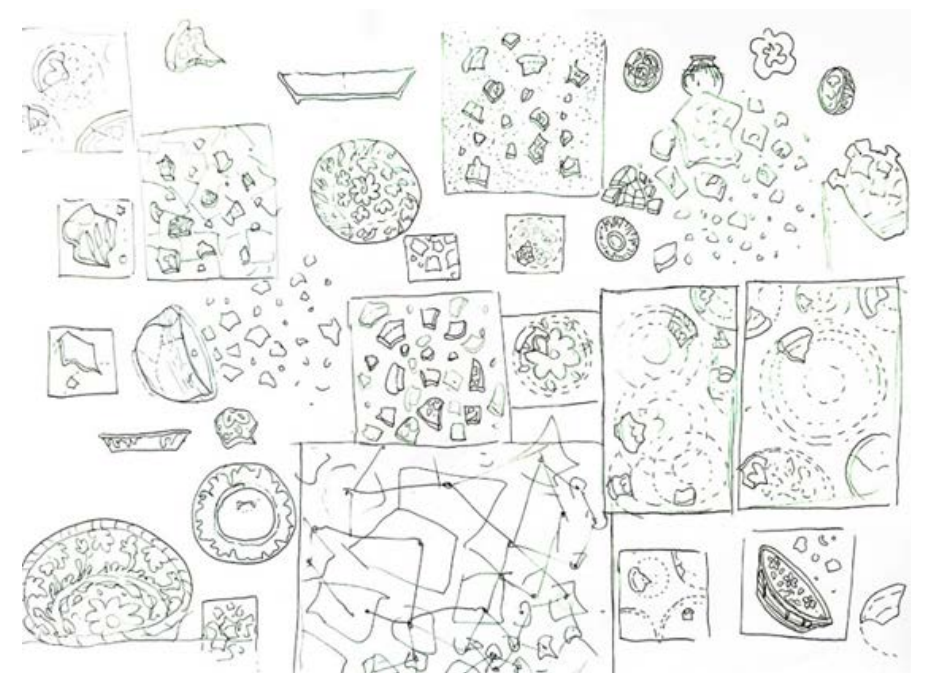

Figura 8. Primeros bocetos realizados en estilógrafo a partir de los restos cerámicos hallados en 2019 y 2020. Fuente: elaboración propia.

Teniendo en cuenta la materia prima y que cada pueblo tenía su cantera de arcilla para elaborar las cerámicas, la elaboración del barro tiene un cariz igualmente simbólico. El plato puede servir para representar un espacio concreto si se utiliza un suelo concreto para hacer el barro, y si se decora dicho plato con las especies que sobre ese suelo viven. Se retrata un lugar de forma ficticia, sin hacer alusión a un lugar o especie concreta, del mismo modo que hacían los artesanos representando flores y aves inspiradas en las naturales.

La reflexión continuada sobre los platos rotos del campo potencia la creencia de que el hombre puede tener un impacto positivo en el medio, favoreciendo el desarrollo de la biodiversidad a través de prácticas agroganaderas preindustriales con tecnología moderna, idea fundamental en la que se sustenta la creación de los nuevos platos. No hay que confundir esta reflexión con la glorificación del pasado, en ningún momento se pretende volver a aquel sistema de producción donde gran parte de la población vivía en condiciones de vida lamentables, sin recursos para vivir cómodamente. Lo que se pretende coger de aquel sistema de producción son las consecuencias positivas de una vida consagrada al trabajo agrícola: germoplasma autóctono y prácticas sostenibles basadas en el saber empírico. La tecnología y los conocimientos que los expertos han desarrollado hoy día pueden ser el mejor hilo conductor de estos saberes de cara a un futuro sostenible.

Pese al gran número de artistas cerámicos habidos y por haber, los referentes artísticos a nivel estético de los diseños propuestos son los ceramistas anónimos, que en sus pequeños talleres 
rurales decoraban los platos de las familias. Por ese motivo, se ha prestado especial atención al lenguaje artístico popular, que además puede contribuir a potenciar el mensaje que habla de la realidad de los pueblos.

\subsection{Resultado de la propuesta artística}

Se han identificado dos tipos de terrenos en el Triángulo CAO, que se pueden dividir a su vez en diferentes subtipos:

-Zonas agrícolas: compuestas por terrenos agrícolas industriales (terrenos erosionados, carentes de biodiversidad), terrenos agrícolas preindustriales (arados, estercolados y sin productos químicos, en su mayoría huertos, así como zonas experimentales) y zonas de ruinas agrarias (cortijos y caseríos abandonados).

-Zonas no agrícolas: compuestas por ecosistemas naturales (vegetación autóctona) y sistemas artificiales (reforestación de pinos, pastos de ganadería extensiva...).

Como ya se ha comentado, los fragmentos ofrecen una gran libertad creativa en la realización de hipótesis visuales. Por ejemplo, en algunas de ellas se podrían ver tardígrados, colémbolos, lombrices y otros pequeños animales que propician, a medida que se integran en la cadena alimentaria, especies de interés cinegético como caracoles, perdices y conejos, además de todo tipo de plantas silvestres con interés cultural y económico (recolección) como son collejas, tagarninas o hinojos. O sea, a través del plato no sólo se puede hacer referencia a la agricultura y la ganadería preindustriales, sino economías domésticas, prehistóricas y continuadas: la recolección y la caza. La agricultura y la ganadería eran parte importante del modo de vida, pero no las únicas; la mayor parte de la población recurría a la caza y la recolección para completar su dieta.

En base a la diferenciación de los terrenos, se ha optado por diseñar tres platos que funcionen como conjunto artístico y que se puedan realizar en barro. Para la elaboración de la materia prima con la que se hacen los platos se cogerán muestras de suelo procedentes de los distintos municipios. Así, se creará un material manufacturado homogéneo, resultante de mezclar suelo de los tres pueblos. El diseño de los mismos girará en torno a las siguientes premisas:

-Un plato representante del Triángulo CAO, como símbolo de unidad de estos tres municipios atendiendo a sus semejanzas históricas rurales. Este plato surge a partir de tres fragmentos encontrados en los distintos municipios, pero que guardan semejanza en la terracota y la ornamentación; concretamente son de un centímetro de grosor y están decorados con la característica ornamentación blanca y azul. En base a estos tres trozos cerámicos se ha realizado una hipótesis visual ficticia que se centra en la forma del triángulo y en los patrones decorativos hallados en los tres pueblos: ornamentaciones vegetales y animales.

-Un plato que representa la erosión y la pérdida de biodiversidad del Triángulo CAO, que no es otra que la que produce la agricultura industrial en todo el mundo. En este caso se cogerá tierra en una zona erosionada de Casabermeja, Antequera y Orce para la elaboración del plato. Potenciando la lectura simbólica, este plato presentaría el característico craquelado de los suelos erosionados. Aunque la información gráfica ocuparía toda la superficie del plato, distaría mucho de presentar los característicos motivos de la cerámica rural popular, habiéndose 
cambiado estos por las fisuras del suelo. La ausencia de biodiversidad se evidencia con la no representación.

-El tercer plato representa los sistemas integrados (permacultura, agricultura regenerativa y agricultura preindustrial de subsistencia), como punto de encuentro entre Humanidad y Naturaleza, de cara a una producción sostenible futura. A diferencia del plato de la erosión, éste se decoraría no solo con especies silvestres, sino con los cultivos y ganados autóctonos. Por ejemplo, en un mismo plato se puede mostrar la compatibilidad del arado con un suelo rico en materia orgánica y vida. Pese a que la comunidad científica recomienda la supresión del laboreo intensivo para frenar la erosión (López Garrido, 2010), el arado con tracción animal, en suelos estercolados y sin fumigar, puede incluso tener impacto positivo, potenciando el desarrollo de flora silvestre, tal y como ha demostrado el trabajo de campo llevado a cabo. Sería un plato realizado con barro de suelos sin fumigar, donde se podría representar un gañán arando con una yunta de mulos. Tras el gañán, multitud de cultivos y flora silvestre, que a su vez alimenta a fauna agraria e incluso ganado. En este ejemplo, el plato representaría la idoneidad de un círculo de producción cerrado: arado-biomasa vegetal-biomasa animal-arado. La forma circular potenciaría también la lectura progresiva de imágenes, exigiendo al espectador la interpretación de la narración completando los huecos entre éstas. Se podría establecer una similitud con el fenaquistoscopio de Plateau en cuanto a la interacción del observador con el mensaje narrativo, aunque en este caso no está implícita la persistencia retiniana ni la restitución del movimiento para la trasmisión del mensaje.
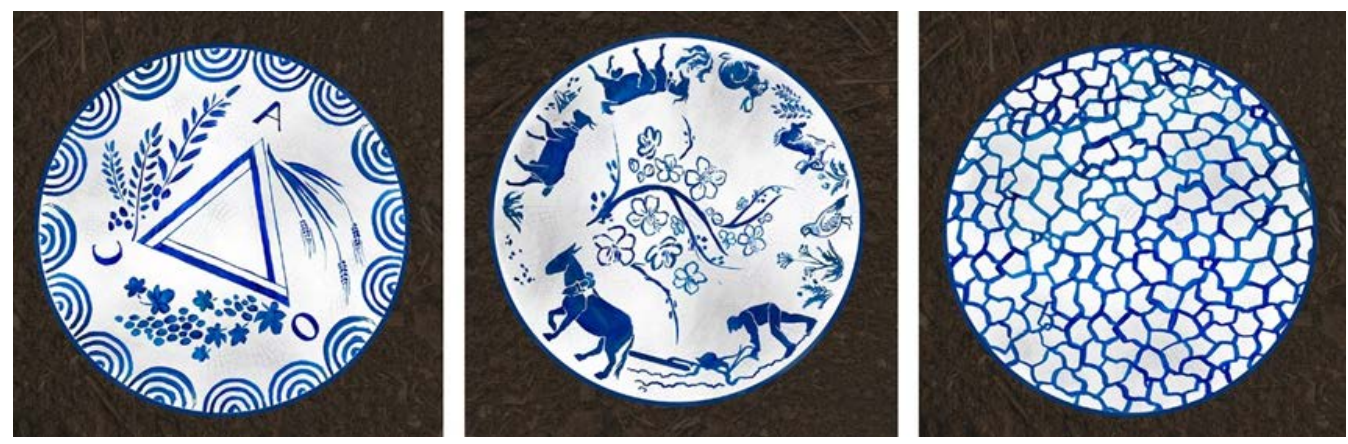

Figura 9. Diseños finales de platos realizados con acrílico azul y montaje digital, 2020. Fuente: elaboración propia.

Estos tres platos (Figura 9) marcan el inicio de una línea de creación artística que puede dar lugar a tres colecciones que trabajen sobre las tres ideas primigenias. La presencia de personas, flora y fauna, así como de objetos (arados, cencerras...) de aquel modo de vida y las tierras de donde proceden las arcillas, permiten todo tipo de decoraciones y mezclas, tantas como se puedan imaginar. También podría contemplarse en el futuro la inclusión de ilustraciones que hablen de las ruinas arquitectónicas producto del éxodo rural, o de los bosques artificiales y su inutilidad.

Tras la elaboración de las cerámicas se realizaría el proyecto expositivo, que en este caso sería sencillo y contendría gran carga simbólica. Sea cual fuese su lugar de exposición, el requisito expositivo sería el mismo: los platos se exhibirían en horizontal, con tierra dentro de ellos perteneciente a cada uno de los municipios, potenciando de esta forma el significado del plato 
como continente y contenido. En él se consume lo que con él se produce, por ejemplo: en una era se comía la llamada "olla de era", que llevaba garbanzos que se habían trillado en la misma era, cultivados en su cercanía. Además, diferentes tipos de tierra dentro de los platos enriquecerían a nivel estético y visual el conjunto. En la Figura 10 se puede ver una recreación de uno de los platos expuesto.

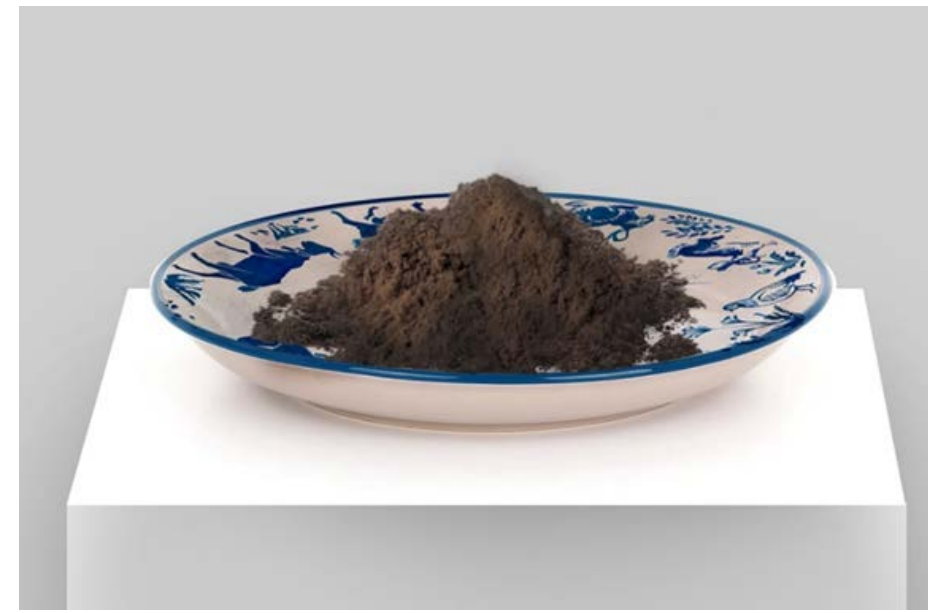

Figura 10. Aproximación digital del montaje definitivo de uno de los platos diseñados. Fuente: elaboración propia.

\section{CONCLUSIONES}

El origen natural y cultural de los fragmentos cerámicos hallados en el Triángulo CAO ha permitido una minuciosa lectura sobre la realidad rural. La misma, ha contribuido a la resignificación simbólica de estas piezas, que a su vez permite la elaboración de un mensaje complejo que contrasta con el uso de técnicas tradicionales. La reflexión filosófica sobre los materiales del campo que llegan a nuestros días (como fragmentos cerámicos o útiles de madera) se hace crucial para la creación tanto del mensaje como del arte que divulga dicho mensaje.

Del mismo modo que en los avances científicos se precisa de un lenguaje matemático pulido durante generaciones, para crear nuevos sistemas de producción sostenibles hay que partir de la base que aportaron los sistemas tradicionales creados a lo largo de la Historia. En este sentido, el trabajo etnográfico y experimental son las mejores herramientas para conocer esta cultura y plasmarla en la creación de una obra artística.

La utilización de los restos llegados al presente de aquella sociedad preindustrial se hace casi obligatoria, pues son los que mejor representan la realidad rural. Ya sean ruinas arquitectónicas, platos cerámicos o cuero, los materiales y recursos que ofrece el agro no solo dotan de estética a las obras artísticas, sino que favorece la meditación sobre los cambios acontecidos en la sociedad rural-urbana en las últimas décadas y las consecuencias sobrevenidas. Los materiales potencian la lectura y el tono del mensaje, en este caso claramente romántico: se habla de la muerte de los pueblos y de la extinción de la biodiversidad. El romanticismo ha inundado el agro con ruinas, veneno y viejos supervivientes de aquel sistema de producción, innegablemente 
duro, pero con menor impacto ambiental que el industrial de hoy día.

La creación de obra artística inspirada en los pueblos es una gran herramienta para evidenciar la problemática y luchar contra el éxodo rural, entre otras cosas. El arte puede transmitir mensajes sociales valiosos, haciendo partícipes a las personas a través de la interpretación artística. Invitar a la reflexión sobre los cambios en el mundo rural y sus consecuencias en el medio ambiente puede ser más útil que simplemente emitir datos sobre el despoblamiento.

La elaboración de hipótesis visuales ficticias a partir de restos cerámicos testigos de la historia más reciente del mundo rural, permite realizar una obra artística gráfica que relaciona el pasado y el presente evidenciando la pérdida y las desventajas del cambio. La huella de una cultura casi extinguida renace fiel a sus orígenes para hacer visible una problemática sobre la que existen propuestas de mejora.

La arqueología del proyecto artístico presentado se construye a nivel gráfico mediante el dibujo tradicional, evidenciando el proceso artístico a seguir en la realización de los platos de las tres colecciones propuestas. El resultado final y el proyecto expositivo puede ser visualizado a través de las recreaciones digitales realizadas, completando el sentido de la obra y evidenciando la proyección y posibilidades de la propuesta.

\section{CONTRIBUCIÓN AUTORES}

Idea, F.L.C.; Revisión de literatura (estado del arte), F.L.C.; Metodología, MC.H.R., F.L.C.; Análisis, F.L.C., MC.H.R.; Resultados, F.L.C., MC.H.R.; Discusión y Conclusiones, F.L.C., MC.H.R.; Redacción (borrador), F.L.C., MC.H.R.; Revisiones finales, F.L.C., MC.H.R.; Diseño del proyecto y patrocinios, F.L.C.

\section{REFERENCIAS}

Acosta-Naranjo, R. (2008). La biodiversidad en la agricultura. La importancia de las variedades locales. En A. González, J. Maestre y A. M. Casas (eds.), Nuevas rutas para el desarrollo en América Latina: experiencias globales y locales (pp. 239-260). México, México: Universidad Iberoamericana.

Anónimo. (1989). Enûma Elish (L. Astey V., trad.). Ciudad de México, México: Universidad Autónoma Metropolitana. (original publicado entre s. XVIII y s. XVII a.C.)

Anónimo. (2003). Poema de Gilgamesh (F. Lara Peinado, ed. y trad.). España: Grupo Anaya; Editorial Tecnos. (original publicado cerca de 2100 a.C.)

Bender, B. (1978). Gatherer-hunter to farmer: a social perspective. World Archaeology, 10(2), 204-222. 
Ceballos, G., Ehrlich, P. R., Anthony, D., Barnosky, A. D., García, A., Pringle, R. M. y Palmer, T. M. (2015). Accelerated modern human-induced species losses: Entering the sixth mass extinction. Science Advances, 1(5). https://doi: 10.1126/ sciadv. 1400253

Ceccon, E. (2008). La revolución verde tragedia en dos actos. Ciencias, 1(91), 21-29.

Chaves, J. (2004). Desarrollo tecnológico en la primera Revolución Industrial. Norba. Revista de Historia, 17, 93-109.

Francé, R. H. (1913). Das Edaphon; Untersuchungen zur Oekologie der bodenbewohnenden Mikroorganismen [EI edafón; Estudios sobre la ecología de los microorganismos que habitan en el suelo]. Munich, Germany: Verlag der Deutschen Mikrologischen Gesellschaft.

González de Molina, M. (coord.). (2014). La cuestión agraria en la historia de Andalucía. Nuevas perspectivas. Sevilla, España: Fundación Pública Andaluza Centro de Estudios Andaluces, Consejería de la Presidencia, Junta de Andalucía.

Hormigón, J. A. (1974). La cerámica, un arte popular en peligro. Triunfo, 591, 34-36.

Hublin, J-J., Ben-Ncer, A., Bailey, S., Freidline, S., Neubauer, S., Skinner, M., Bergmann I., Le Cabec, A., Benazzi S., Harvati K. y Gunz P. (2017). New fossils from Jebel Irhoud, Morocco and the pan-African origin of Homo sapiens. Nature, 546, 289-292. https://doi:10.1038/nature22336

Irwin, R. L. (2013). La práctica de la a/r/tografía (D. García Sierra, trad.). Revista Educación y Pedagogía, 25(65), 106-113.

Jordan, P. y Zvelbil, M. (2009). Ceramics Before Farming. The Dispersal of Pottery Among Prehistoric Eurasian HunterGatherers. London, England: Institute of Archaeology, University College London.

López Garrido, R. (2010). Laboreo de conservación: efectos a corto y largo plazo sobre la calidad del suelo y el desarrollo de los cultivos [tesis doctoral no publicada, Universidad de Sevilla]. Depósito de Investigación de la Universidad de Sevilla. https:// idus.us.es/handle/11441/71158

Luque-Cuesta, F. y Hidalgo-Rodríguez, M. C. (2020). El arte como divulgador cultural del mundo rural: Una novela gráfica sobre 
las consecuencias culturales y ambientales de la agricultura industrial. En A. M. de Vicente y N. Abuín (Coords.), La comunicación especializada del siglo XIX. Vol. 1. (pp. 999-1024). Madrid: Editorial McGraw-Hill.

Manrique, L. (2015). El Antropoceno: La era de la depredación. Política Exterior, 29(165), 170-174.

Martínez-Alier, J. (2005). El ecologismo de los pobres: resistencia popular e indígena contra el expolio de las transnacionales. EI Ecologista, 45, 41-43.

Martínez-Centeno, A. L. y Huerta-Sobalvarro K. K. (2018). La revolución verde. Revista Iberoamericana de Bioeconomía y Cambio Climático, 4(8), 1040-1052. https://doi.org/10.5377/ ribcc.v4i8.6717

Mattison, S. (2003). The Complete Potter: The Complete Reference to Tools, Materials and Techniques for All Potters and Ceramicists. USA: Barron's Educational Series Publishing.

Mella Márquez, J. M. (2011). La innovación en la cerámica artesanal. Madrid, España: Subdirección General de Desarrollo Normativo, Informes y Publicaciones.

Molina-González, I, Moreno-Aragón, P, Montijano-García, J. M. y Soriano-Bueno, J. (2000). Cortijos, haciendas y lagares. Arquitectura de las grandes explotaciones agrarias en Andalucía. Provincia de Málaga. Andalucía, España: Junta de Andalucía. Consejería de Obras Públicas y Transportes.

Ovidio, P. (1983). Metamorfosis (A. Ruiz de Elvira, trad.). Barcelona, España: Editorial Bruguera S.A. (original publicado en el año 8 d. C.)

Orton, C., Vince, A. \& Tyers, P. (1997). La cerámica en arqueología. Ciudad: Editorial Crítica.

Reijnders, A. (2005). The Ceramic Process: A Manual and Source of Inspiration for Ceramic Art and Design. USA: University of Pennsylvania Press.

Testart, A. (1988). Some Major Problems in the Social Anthropology of Hunter-Gatherers [and Comments and Reply]. The University of Chicago Press. Current Anthropology, 29(1), 1-31.

Thode, R \& López, F. (1999, enero). Jnum. La Tierra 
de los Faraones. https://egiptologia.org/?page_

id=2055\#: :text=Seg\%C3\%BAn\%20una\%20leyenda\%20

Jnum\%20originalmente,sin\%20necesidad\%20de\%20su\%20

intervenci\%C3\%B3n

Wrangham, R. (2009). Catching fire: how cooking made us human. England: Profile Books.

Wu, X., Zhang C., Goldberg P., Cohen, D., Pan, Y., Arpin T. y BarYosef, O. (29 de junio de 2012). Early Pottery at 20,000 Years

Ago in Xianrendong Cave, China. Science, 336(6089), 1696-1700.

https://doi: 10.1126/science.1218643 